Richards, L. ; Richards, B.S. ; Schäfer, A.I. ; (2011)

\section{Salt and inorganic contaminant removal by renewable energy powered nanofiltration/reverse osmosis}

Laura A. Richards ${ }^{1,2}$, Bryce S. Richards ${ }^{1}$, Andrea I. Schäfer ${ }^{2 *}$

${ }^{1}$ School of Engineering and Physical Sciences, Heriot-Watt University, Edinburgh, EH14 4AS, United Kingdom

${ }^{2}$ School of Engineering, The University of Edinburgh, Edinburgh, EH9 3JL, United Kingdom

*Corresponding author: Andrea Schäfer. E-mail: Andrea.Schaefer@ed.ac.uk; Phone: +44 131650 7209; Fax: +44 1316506781

Submitted to

Journal of Membran

September 2010

\section{Abstract}

The objective of this study was to evaluate the effects of fluctuating energy and $\mathrm{pH}$ on retention of dissolved contaminants from real Australian groundwaters using a solar (photovoltaic) powered ultrafiltration - nanofiltration/reverse osmosis (UF-NF/RO) system. Four NF/RO membranes (BW30, ESPA4, NF90, and TFC-S) were used. Energy fluctuations affected pressure and flow. Solar irradiance levels impacted retention of fluoride, magnesium, nitrate, potassium, and sodium where convection/diffusion dominated retention. Retention of calcium, strontium, and uranium was very high and independent of solar irradiance, which was attributed to a combination of size and charge exclusion and for some solutes sorption and precipitation. Groundwater characteristics affected retention and the solutes were categorized into two groups according to retention as a function of $\mathrm{pH}$ : (1) $\mathrm{pH}$ independent retention (arsenic, calcium, chloride, nitrate, potassium, selenium, sodium, strontium, and sulfate); and (2) $\mathrm{pH}$ dependent retention (copper, magnesium, manganese, molybdenum, nickel, uranium, vanadium, and zinc). retention (coppe, magnesiun, manganese, molybenum, nickel, uranium, vanadium, and zinc) The retention of Group 1 solutes was typically high and attributed to steric effects. Group 2 solutes had dominant, insoluble species under certain conditions which led to deposition on the membrane surface (and thus varying apparent retention). The renewable energy membrane system removed a large number of groundwater solutes reliably over a range of real energy and $\mathrm{pH}$ conditions.

\section{Keywords}

Nanofiltration, reverse osmosis, inorganic contaminant removal, photovoltaics, groundwater

\section{Introduction}

Drinking water treatment and energy consumption are integrally related and need to be addressed together in order to achieve all the United Nations' Millennium Development Goals [1]. A concern with remote drinking water supplies is the presence of naturally-occurring salts and inorganic contaminants (such as arsenic, calcium, chloride, copper, fluoride, magnesium, manganese, molybdenum, nickel, nitrate, potassium, selenium, sodium, strontium, sulfate, uranium, vanadium, and zinc), which can be undesirable above guideline values for both health and aesthetic reasons [2,3]. Nanofiltration/reverse osmosis (NF/RO) is capable of retaining many of these salts and inorganic contaminants, and NF/RO coupled with a renewable energy source may help address drinking water treatment in remote areas without electrical grid connections.

$\mathrm{NF} / \mathrm{RO}$ utilizes a number of mechanisms to retain salts and inorganic contaminants, which are no widely understood in real groundwaters. One of the prevailing mechanisms (and only established non-sieving mechanism) is the Donnan equilibrium, created by charge interactions between the charged membrane surface and counter- and co-ions present in solution [4-7]. The Donnan potential is impacted by surface charge and chemistry (membrane specific), feed water composition (including $\mathrm{pH}$, electrolyte concentrations, and ionic strength), as well as flux and hydrodynamic conditions [5-8]. The membrane charge density depends on ionic strength and concentration, and can be partially attributed to ion adsorption on the membrane surface [9].

Size exclusion is another important mechanism of NF/RO. Ion transport is significantly impacted by hydrated radii and hydration strength because size variations can determine which ions are able to pass through the membrane pores via convection or diffusion $[6,10,11]$. Ions with able to pas the relatively smaller crystal radii have higher charge, higher hydration numbers, larger hydrated radii, and hold hydration shells weaker hydration shells and smaller hydrated radil, and hence may be able to detach from their hydration layer when passing through the membrane [6]. Hydration strength is impacted by ionic structure and solution composition as well as environmental factors such as $\mathrm{pH}$, ionic strength, and temperature [6].

Accumulation on the membrane surface can result from precipitation due to concentrations at the membrane surface exceeding solubility limits [12]. Deposit formation and the possible consequent variation of membrane characteristics affect apparent retention. The actual concentration at the surface (or boundary layer concentration) depends on membrane characteristics, solution chemistry (e.g. feed concentration and $\mathrm{pH}$ ), and operating conditions (e.g. pressure, cross flow velocity, hydrodynamics), and cannot be measured. Deposition on the (e.g. pessure con membrane surface can result in membrane scaling, which reduces permeate flux and quality, requires chemical cleaning, and may lead to physical damage of the membranes and hence a reduced lifetime.

The feed $\mathrm{pH}$ (which varies widely in real groundwater) dictates compound protonation and speciation. The speciation of a compound varies due to oxidation-reduction transformations an the number of hydrogen atoms available for bonding. The resulting species affects the retentio mechanisms [5,13-16]. The dominant retention mechanism further depends on the specific compound characteristics, feed solution chemistry, membrane characteristics (especially charge), and operational parameters (in particular applied pressure) [11,13,15, 17-23]. Theoretical models using the extended Nernst-Plank equation have been used to predict the relative influence 
Richards, L. ; Richards, B.S. ; Schäfer, A.I. ; (2011)

Renewable energy powered membrane technology: Effect of contaminant speciation on retention and membrane deposition,

of contributing mechanisms, namely convection (pressure gradient), diffusion (concentration gradient) and electromigration (electric potential gradient) [4, 24-27].

Variable energy input from a renewable energy system will vary operation (in particular flow and pressure) [28] and subsequently may impact salt and inorganic contaminant retention due to changing conditions near the membrane surface. In consequence, the objective of this study was to evaluate retention of a number of natural solutes using NF/RO with regard to three specific aims, namely to understand (i) the impact of energy fluctuation on retention; (ii) the role of $\mathrm{pH}$ in this process; and (iii) the dominant mechanisms of retention in real groundwater.

\section{Experimental}

Brackish groundwaters at two locations in central Australia (Pine Hill and Ti Tree Farm) were used [29]. An overview of average feed water composition at both Pine Hill and Ti Tree on the days of experimentation, detection limits, and both Australian and World Health Organization (WHO) drinking water guidelines is provided in Table 1. Most contaminants at Pine Hill were below Australian health-based guidelines [3], with the exception of selenium $(0.015 \mathrm{mg} / \mathrm{L}$, guideline (GL): $0.01 \mathrm{mg} / \mathrm{L})$, sulfate $(889 \mathrm{mg} / \mathrm{L}, \mathrm{GL}: 500 \mathrm{mg} / \mathrm{L})$, and uranium $(0.295 \mathrm{mg} / \mathrm{L}$, GL: $0.02 \mathrm{mg} / \mathrm{L}$ ). At Ti Tree, all contaminants were below Australian health-based guidelines excep nitrate $(58.4 \mathrm{mg} / \mathrm{L}, \mathrm{GL}: 50 \mathrm{mg} / \mathrm{L})$ and uranium $(0.025 \mathrm{mg} / \mathrm{L}, \mathrm{GL}: 0.02 \mathrm{mg} / \mathrm{L})$. Total dissolved solids (TDS) was calculated from conductivity as described by Schäfer et al. [30].

\section{(Table 1)}

Experiments were conducted using a solar powered ultrafiltration and NF/RO system comparing four NF/RO membranes (BW30, ESPA4, NF90, and TFC-S). The development, design details and general performance of the system have been published previously $[28,30]$. Samples were and general performance of the system have been published previously $[28,30]$. Samples were collected from feed, UF permeate, $\mathrm{NF} / \mathrm{RO}$ permeate, and concentrate. Both $\mathrm{NF} / \mathrm{RO}$ perme
concentrate were recirculated into the $250 \mathrm{~L}$ feed tank and fresh water was used each day.

Two types of experiments were conducted: (1) solar experiments and (2) pH experiments. The solar experiments were designed to assess the impact of naturally fluctuating energy throughout a solar day on salt/contaminant retention at the natural $\mathrm{pH}$ of the water. The results of solar experiments presented are for BW30 at Pine Hill. During the solar experiments, samples were collected every hour because the operating conditions (flow and pressure) were dependent on the solar conditions at the time of sampling. The temperature of the feed water increased from 24.7 to $31.6^{\circ} \mathrm{C}$ during the solar day due to changes in ambient temperature and pumping heat.

The objective of the $\mathrm{pH}$ experiments was to evaluate the specific impact of $\mathrm{pH}$ on contaminant retention, while using constant power (supplied from a diesel generator) to ensure that flow and pressure remained constant, thus isolating $\mathrm{pH}$ as the only variable. For the $\mathrm{pH}$ experiments, each of the four membranes was used at Pine Hill (for membrane performance comparison) and an additional experiment with BW30 was conducted at Ti Tree (for comparison of different groundwaters). During each $\mathrm{pH}$ experiment, the $\mathrm{pH}$ of the bore water was adjusted in increasing step-wise increments between 3 and 11 with $\mathrm{HCl}$ and $\mathrm{NaOH}(1 \mathrm{M})$ and equilibrated (typically for 30-60 minutes) before taking performance readings and collecting samples for analysis. Operating parameters for the $\mathrm{pH}$ experiments were set at $9 \mathrm{bar}$ and $400 \mathrm{~L} / \mathrm{h}$. The feed water temperature ranged from 24.2 to $26.9^{\circ} \mathrm{C}$ at Pine Hill and from 29.1 to $32.6^{\circ} \mathrm{C}$ at Ti Tree on the days of experimentation.
Each sample was filtered and divided into two portions for subsequent analysis. Sample portions for cation analysis were preserved with $\mathrm{HNO}_{3}(1 \% \mathrm{v} / \mathrm{v})$, and portions for anion analysis were not acidified. For the $\mathrm{pH}$ experiments, chemical analysis was completed by the Australian Nuclear Science and Technology Organisation (ANSTO). Cation analysis was performed using inductively coupled plasma atomic emission spectroscopy (ICP-AES) (Varian Vista AX Simultaneous CCD) and inductively coupled plasma atomic mass spectroscopy (ICP-MS) (Agilent 4500), and anion analysis was performed by ion chromatography (Dionex DX-600 with EG40 Eluent Generator). All samples were analyzed quantitatively by external calibration. ICPAES samples were spiked ( $4000 \mathrm{mg} / \mathrm{L}$ ) with cesium to suppress easily ionised elements, and ICPMS samples were spiked with indium, yttrium, lithium, scandium, lutetium, bismuth, and rhodium as internal standards. Cation analysis included aluminum, arsenic (total), barium, rhodium as internal standards. Cation analysis included aluminum, arsenic (total), barium,
beryllium, calcium, chromium, copper, iron, lead, lithium, magnesium, manganese, molybdenum, beryllium, calcium, chromium, copper, iron, lead, lithium, magnesium, manganese, molybdenur,
nickel, potassium, selenium, sodium, strontium, sulfur, titanium, uranium, vanadium, and zinc. nickel, potassium, selenium, sodium, strontium, sulfur, titanium, uranium, vanadium, and zinc.
Anion analysis included chloride, nitrate, and sulfate. Cations for the solar experiments were analyzed using ICP-MS (Agilent $7500 \mathrm{ce}$ ) at the University of Edinburgh. Fluoride measurements were taken on-site for solar experiments only using an ion selective electrode (Metrohm, Ltd.). Duplicate samples, analysis blanks, and certified reference standards were analyzed for quality control. Detection limits for each salt/contaminant are included in Table 1. Additionally, Visual MINTEQ software (version 2.53) was used to predict the speciation of solutes at Pine Hill and was previously described in detail [14].

\section{Results and Discussion}

\subsection{Performance under Fluctuating Solar Conditions}

Understanding the impact of fluctuating solar energy on inorganic contaminant removal is critical to evaluating the performance of the membrane system and to determine the safe operating window. During periods of highest solar irradiance, power generation from the pump increases, leading to maximum pressure, flow, and therefore flux while during cloudy periods, pressure and flow decrease and sufficiently low energy levels will lead to pump shut down. Inevitably such fluctuations will affect the retention of solutes.

Changes in solar irradiance throughout the day at Pine Hill correlated directly with flow, flux and pressure (Figure 1A and B), as expected for a system with no energy storage [28]. The temperature of the feedwater increased nearly $7^{\circ} \mathrm{C}$ during the day due to increasing ambient temperature (data not shown on Figure 1). The relationship between solar irradiance and retention of common salts (calcium, magnesium, sodium, potassium, and TDS) and inorganic contaminants (uranium, strontium, fluoride, and nitrate) using BW30 is shown in Figure $1 \mathrm{C}$ and contaminants ( respective Re $\mathrm{D}$, respectively. Retention was high and solute specific, with average retention throughout the day being: strontium $(99.9 \pm 0.1 \%) \geq$ calcium $(99.9 \pm 0.1 \%) \geq$ uranium $(99.9 \pm 0.2 \%)>$ fluoride $(98.5 \pm 1.0 \%)>$ magnesium $(98.1 \pm 1.9 \%)>\operatorname{sodium}(97.1 \pm 1.4 \%)>\operatorname{potassium}(96.7 \pm 1.3 \%)>$ $>$ nitrate $(92.0 \pm 1.8 \%)$ while TDS was $96.5 \pm 3.5 \%$.

\section{(Figure 1)}

Comparison of retention trends with solar irradiance (and thus with flow and pressure) gives information on mechanisms. The retention of some of these salts and contaminants (strontium, calcium, and uranium) was very high ( $>99.5 \%)$ and did not change with solar irradiance. Under the conditions of the experiment at Pine Hill $(\mathrm{pH}$ 7.2), the dominant species of strontium and 
Richards, L. ; Richards, B.S. ; Schäfer, A.I. ; (2011)

calcium are $\mathrm{Sr}^{2+}$ and $\mathrm{Ca}^{2+}$, respectively [14], both of which have large hydrated radii of $0.412 \mathrm{~nm}$ (see Table 2) [31]. The large hydrated radii suggest that strontium and calcium retention is dominated by size exclusion. This is significant because safe permeate concentrations of strontium, calcium, and uranium would therefore be expected regardless of operating conditions. The speciation and behavior of uranium specifically is dealt with in more detail by Rossiter et al. [32].

(Table 2)

The retention of the other salts and contaminants was impacted by changing solar irradiance. The retention of nitrate, potassium, sodium, and TDS closely followed the trend in solar irradiance, with lowest retention occurring during the lowest solar irradiance both in the morning and with lowest retention occurring during the lowest solar irradiance both in the morning and
evening. The hydrated radii (see Table 2$)$ of nitrate $(0.335 \mathrm{~nm})$, potassium $(0.331 \mathrm{~nm})$, and evening. The hydrated radii (see Table 2$)$ of nitrate $(0.335 \mathrm{~nm})$, potassium $(0.331 \mathrm{~nm})$, and sodium $(0.358 \mathrm{~nm})$ are relatively low, hence the operating conditions are more influential on retention than they were for the larger hydrated ions. Convection/diffusion dominate retentio for nitrate, potassium, and sodium as is evidenced by increasing retention with increasing pressure. Similar behavior has been previously observed and attributed to convection/diffusion, especially for contaminants with small hydrated size (and thus can enter the membrane 'pore') [15]. As pressure increases, convective drag forces increase due to the solvent flux in the pore even though surface forces attracting the solute stay constant. Up until a threshold pressure, the surface forces are stronger than the drag forces, and therefore ion flux remains low while solvent flux still increases with pressure, and thus retention increases [15]. Even at the lowest solar irradiance, the lowest retention observed was $88 \%$ for nitrate, which indicates that removal acceptable to guideline values could be achieved for waters of much higher feed concentration.

The retention of fluoride and magnesium closely followed solar irradiance at the beginning of the day, which is explained again by convection/diffusion. However, at the end of the day, retention did not again drop as was observed with nitrate, potassium, and sodium. This could be attributed to concentration polarization and/or changes in the membrane surface which resulted in nearly constant retention in the evening despite the decrease in solar irradiance. Correlation of flow and fluoride retention (as observed in the morning) has been similarly reported and attributed to convection/diffusion [33].

\subsection{System Performance for $\mathrm{pH}$-independent Solutes}

The results from the $\mathrm{pH}$ experiments were categorized into two groups according to observed retention behaviour. Group 1 contains solutes whose retention was independent of $\mathrm{pH}$ (arsenic, calcium, chloride, nitrate, potassium, selenium, sodium, strontium, and sulfate). Average calcium, chloride, nitrate, potassium, selenium, sodium, strontium, and sulfate). Average retention for each Group 1 solute, membrane, and location throughout the entire $\mathrm{pH}$ range are reported in Table 3. Results will first be dis the other membranes and location.

(Table 3)

Group 1 retention using BW30 at Pine Hill was high and generally above $90 \%$ (Table 3 ). Retention correlated both with charge and hydrated size. The hydrated radii sequence for the predicted dominant species of each solute (no data available for arsenic species) is: $\mathrm{Ca}^{2+}(0.412$ $\mathrm{nm})=\mathrm{Sr}^{2+}(0.412 \mathrm{~nm})>\mathrm{SeO}_{4}{ }^{2-}(0.384 \mathrm{~nm})>\mathrm{SO}_{4}{ }^{2-}(0.379 \mathrm{~nm})>\mathrm{Na}^{+}(0.358 \mathrm{~nm})>\mathrm{NO}_{3}{ }^{-}(0.335)$ $>\mathrm{Cl}^{-}(0.332)>\mathrm{K}^{+}(0.331)$ (Table 2) [14,31]. Hydrated radii data as a function of $\mathrm{pH}$ is not available in the literature for these solutes. Multivalent ions with large hydrated radii (i.e. $\mathrm{Ca}^{2+}$, $\mathrm{Sr}^{2+}$ and $\mathrm{SO}_{4}{ }^{2-}$ ) were retained more than monovalent ions with smaller hydrated radii (i.e. $\mathrm{Cl}^{-}, \mathrm{K}^{+}$ and $\mathrm{Na}^{+}$) at Pine Hill with BW30 (Table 3).

As the charge of BW30 (as well as each of the other membranes) becomes increasingly negative with increasing $\mathrm{pH}$ [34], if charge exclusion was the dominant retention mechanism, retention would be expected to consequently increase with $\mathrm{pH}[8]$. However, because retention did not change with $\mathrm{pH}$, charge is not predicted to be the dominant mechanism for these salts and inorganic contaminants. This is best exemplified with chloride, nitrate, potassium, and sulfate, whose speciation is mostly $\mathrm{pH}$ independent between $\mathrm{pH}_{3}$ and 11 under the conditions at Pine Hill, with dominant species $\mathrm{Cl}^{-}, \mathrm{NO}_{3}^{-}, \mathrm{K}^{+}$, and $\mathrm{SO}_{4}^{2-}$, respectively [14]. The retention of these

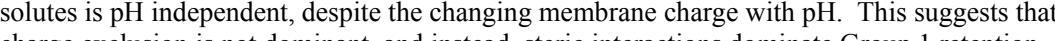
charge exclusion is not dominant, and instead, steric interactions dominate Group 1 retention. This is supported because the highest retention is achieved for those with higher hydrated radii. Further, a previous study has shown that nitrate transport in the pore is dominated by diffusion [27].

The speciation of other Group 1 solutes (arsenic, calcium, selenium, sodium, and strontium) depended on $\mathrm{pH}$ [14], but despite the changes in dominant species (and thus differences in charge and hydrated size), the retention remained $\mathrm{pH}$ independent. The dominant species of calcium, sodium, and strontium were carbonate forms [14] at high $\mathrm{pH}$ and arsenic likely deprotonated between $\mathrm{pH} 7$ and 9 depending on if arsenic was present as arsenic(V), arsenic(III) or a mixture [35]. Arsenic (III) retention has been previously observed to be $\mathrm{pH}$ independent and attributed to steric exclusion [16]. Regardless of these changes in species (corresponding to changes in hydrated size and charge) with $\mathrm{pH}$, retention was still constant and for each of these solutes, hydrated size and charge) with $\mathrm{pH}$, retention was still constant
again supporting that steric interactions dominated retention.

The results for Group 1 solutes with health-based Australian or WHO guidelines (arsenic, nitrate, selenium, and sulfate - see Table 1) warrant individual attention given their significance in water supplies. With BW30, the retention of these contaminants was high. Arsenic (total) was wellretained, with an average retention $\geq 78.9 \%$ (limited by analytical detection limit). High retention of nitrate $(90.6 \%)$ was achieved. Selenium and sulfate were the only contaminants above the guideline in the feed, and high retention was again achieved $(\geq 93.8 \%$ and $99.5 \%$, respectively), resulting in permeate concentrations well below the guideline. Again, selenium and sulfate have relatively high hydrated radii ( 0.384 and 0.379 , respectively) [31], which supports that their high retention is due to size exclusion.

Membrane comparison (Table 3) showed the TDS retention sequence for Pine Hill is: TFC-S $(77.7 \pm 2.7 \%)<$ ESPA4 $(87.7 \pm 5.9 \%)<\mathrm{NF} 90(91.4 \pm 3.7 \%)<\mathrm{BW} 30(94.9 \pm 4.5 \%)($ note TDS has higher uncertainty than the other parameters because of the many groundwater constituents contributing to this measurement and the changes in their proportion in feed/permeate). The average daily flux sequence (data not shown) is inverse to the TDS retention: BW30 (13.5 \pm 1.5 $\left.\mathrm{L} / \mathrm{m}^{2} . \mathrm{h}\right)<\operatorname{ESPA} 4\left(23.1 \pm 1.2 \mathrm{~L} / \mathrm{m}^{2} . h\right)=\mathrm{NF90}\left(23.1 \pm 0.6 \mathrm{~L} / \mathrm{m}^{2} . h\right)<\mathrm{TFC}-\mathrm{S}\left(24.3 \pm 0.4 \mathrm{~L} / \mathrm{m}^{2} . h\right)$ The retention of specific solutes follows the same trend as TDS for each membrane (see Table 3 ). The lowest retentions occur with TFC-S (which is the 'loosest' of the membranes), and the highest retentions with BW30 (a 'tight' brackish water RO membrane). 
Richards, L. ; Richards, B.S. ; Schäfer, A.I. ; (2011)

Some of these ions presented challenges to the 'loose' TFC-S membrane in terms of retention. In particular, nitrate retention $(51.5 \%)$ and arsenic retention $(64.2 \%)$ by TFC-S were low as compared to the retention of other contaminants by TFC-S and to the other membranes' retention of arsenic and nitrate. Because feed concentrations of nitrate and arsenic did not exceed guidelines, this was not unsafe, although the lower retention with TFC-S could be an issue for waters of higher feed concentrations. Size exclusion was a less effective retention mechanism for the 'loose' TFC-S, which explains the lower retention observed and highlights that variation of the effective membrane 'pore' size as compared to contaminants' hydrated radii was significan when different membranes are considered. Retentions with BW30 and NF90 are very similar, which can be explained by the comparable molecular weight cut off values of these membranes (98 and 100, respectively) [34] (and thus similar 'pore' size).

Comparing Pine Hill and Ti Tree waters (Table 3) shows the impact of general water characteristics on the performance of BW30. Group 1 retention trends at Ti Tree confirmed results seen at Pine Hill ( $\mathrm{pH}$ independence and similar retention values). This indicates the consistently high performance of BW30 with Group 1 solutes, and again supports that size exclusion is predominant because of the minimal impact of feed composition. The difference in feed temperature $\left(31.0^{\circ} \mathrm{C}\right.$ at Ti Tree compared to $23.8^{\circ} \mathrm{C}$ at Pine Hill) did not have an observable impact on retention. Nitrate data is of particular significance because it was present above guidelines at Ti Tree, and was safely removed to near detection limit. Retention values for those solutes whose permeate measurements were limited by detection (arsenic and selenium) are difficult to compare between groundwaters, but both arsenic and selenium were well below guidelines at Ti Tree.

\subsection{Behavior of pH-dependent Solutes}

Group 2 solutes (copper, magnesium, manganese, molybdenum, nickel, uranium, vanadium, and zinc) have insoluble and dominant species under certain conditions, which resulted in their apparent retention being dependent on $\mathrm{pH}$ (Figure 2). Feed concentration (and thus apparen retention) varied significantly between $\mathrm{pH} 3$ and 11, because of deposition on the membrane surface rather than charge or steric retention mechanisms. Precipitation occurs when concentration in the boundary layer exceeds the solubility limit of a particular species [5] at those local conditions.

\section{(Figure 2)}

Magnesium (Figure 2B), for example, showed a drastic drop in feed concentration above $\mathrm{pH} 10$, indicating precipitation due to the insolubility of $\mathrm{MgCO}_{3}[12,14]$. Deposit of precipitates $\left(\mathrm{M}_{\mathrm{dep}}\right)$ can be calculated from the mass balance:

$$
M_{\text {dep }}=V_{F, I} C_{F, I}-V_{F} C_{F}-V_{P} C_{P}-V_{N} C_{N} \quad \text { (Eqn. 1) }
$$

where $\mathrm{V}$ is volume, $\mathrm{C}$ is concentration, and indices $\mathrm{F}$ are feed, $\mathrm{P}$ permeate, $\mathrm{N}$ concentrate, and $\mathrm{I}$ the initial reference condition, respectively. Indeed, the mass balance confirmed accumulation on the NF/RO membrane surface, with approximately $78 \%$ of the magnesium present in the initial feed solution having deposited at high $\mathrm{pH}$.

Similarly to magnesium, deposition occurred for all of the other contaminants shown in Figure 2. Manganese (Figure 2C) and nickel (Figure 2E) deposited on the membrane at high $\mathrm{pH}$, with respective accumulations of $\geq 50 \%$ and $\geq 3 \%$ the original concentrations (calculation limited by detection). Speciation models indicated that these solutes were present in their carbonate form $\mathrm{MnCO}_{3}(\mathrm{aq})$ and $\mathrm{NiCO}_{3}(\mathrm{aq})$ at the $\mathrm{pH}$ values where precipitation was observed [14]. Copper (Figure 2A) and molybdenum (Figure 2D) both accumulated on the membrane below $\mathrm{pH} 7$, with respective accumulations of $\geq 68 \%$ and $\geq 42 \%$ (again constraint by analytical detection limit). Copper was present as either $\mathrm{CuCl}^{2-}$ or $\mathrm{CuCl}_{2}{ }^{-}$, depending on the valence of copper (which was not determined) and molybdenum as $\mathrm{MoO}_{3}\left(\mathrm{H}_{2} \mathrm{O}\right)_{3}(\mathrm{aq})$. Accumulation of zinc (Figure 2H) was the most significant, with $\geq 96 \%$ of the original concentration accumulating on the membrane above $\mathrm{pH} 8$, where zinc was mostly $\mathrm{Zn}(\mathrm{OH})_{2}(\mathrm{aq})$ and $\mathrm{ZnCO}_{3}(\mathrm{aq})$ between $\mathrm{pH} 8$ and 10 , and $\mathrm{Zn}$ $\left(\mathrm{CO}_{3}\right)_{2}^{-2}$ above $\mathrm{pH} 10$ [14]. Vanadium (Figure 2G) showed complex speciation with deposition occurring both at low and high $\mathrm{pH}$ (accumulation $\geq 34 \%$ ). Deposition of urium (Figure 2H) occurring both at low and high $\mathrm{pH}$ (accumulation $\geq 34 \%$ ). Deposition of uranium (Figure $2 \mathrm{H}$ ) on the membrane occurred above $\mathrm{pH} 5$, and the complex speciation of uranium suggests it would dissolve back into solution above pH $8[14,36]$, which was not observed at Pine Hill with BW30.
The behavior of uranium specifically was published elsewhere [32].

Removal was achieved (mostly to detection limit) for Group 2 solutes with health-based guidelines (copper, manganese, molybdenum, nickel and uranium - see Table 1). Uranium removal to below the guideline is especially notable since the feed concentration was significantly above the recommended level. Although the feed concentrations of copper, molybdenum and nickel did not exceed guidelines, the high removal observed indicates that the process would be effective in treating waters with higher feed concentrations of these solutes. The same general trends were observed for the other membranes tested at Pine Hill (TFC-S, ESPA 4, and NF90) as well as for BW30 at Ti Tree.

Long term consequences of membrane deposition are flux decline, possible deterioration in permeate quality, and increased specific energy consumption (SEC). During the relatively short experiments (30-60 minutes per $\mathrm{pH}$ value), significant flux decline (data not shown) at high $\mathrm{pH}$ was noted for BW30 at both Pine Hill (46\%) and Ti Tree (25\%). Flux decline for the other membranes was less than $10 \%$. The lowest overall flux $\left(13.5 \mathrm{~L} / \mathrm{m}^{2} . \mathrm{h}\right)$ with BW30 at Pine Hill corresponded to the highest SEC $(1.9 \mathrm{~W} . \mathrm{L} / \mathrm{h})$. This was due to the high salt concentrations at Pine Hill (for example calcium in Pine Hill water is approximately double that of Ti Tree water, see Table 1), in addition to the high retention of BW30 as compared to the other membranes tested which results in higher concentration polarization, higher osmotic pressure and consequently lower flux (which directly impacts SEC). Much of the precipitation was reversible with a change in $\mathrm{pH}$ (see vanadium on Figure $2 \mathrm{G}$ ) which may not be the case during long term operation when biofouling may occur as well.

\section{Conclusions}

In summary, all solutes were well-retained ( $\geq 85 \%$ ) during a typical daily range of solar irradiance conditions. Energy variation (solar irradiance between 0.2 and $1.0 \mathrm{~kW} / \mathrm{m}^{2}$ ) changed flow and pressure and hence impacted retention for fluoride, magnesium, nitrate, potassium, an sodium where convection/diffusion dominated retention. For very large hydrated solutes (calcium, strontium, and uranium), retention was very high due to size exclusion and no impact of operating conditions was observed.

Retention of a number of solutes (Group 1: arsenic, calcium, chloride, nitrate, potassium, selenium, sodium, strontium, and sulfate) was $\mathrm{pH}$ independent (between $\mathrm{pH} 3$ and 11). Because retention was stable despite changes in the membrane surface charge (and thus changing electric 
Richards, L. ; Richards, B.S. ; Schäfer, A.I. ; (2011)

Renewable energy powered membrane technology: Effect of contaminant speciation on retention and membrane deposition,

interactions), steric effects are predicted to govern retention. Retention with BW30 at Pine Hill ranged from $\geq 78.9 \%$ (arsenic) to $99.6 \%$ (strontium and calcium) which was attributed to differences in solute properties (e.g. hydrated size).

Retention of other solutes (Group 2: copper, magnesium, manganese, molybdenum, nickel, uranium, vanadium, and zinc) varied as a function of $\mathrm{pH}$ due to speciation. Deposition on the membrane surface occurred when concentrations at the membrane surface exceeded solubility limits, and resulted in flux decline. This is a practical problem for long-term operation.

In conclusion, the renewable energy membrane system reliably removed salts and inorganic contaminants over a range of real energy and $\mathrm{pH}$ conditions via convection/diffusion and precipitation mechanisms. This has important implications for remote water applications where such contaminants that are difficult to remove by conventional technologies are a concern.

\section{Acknowledgements}

The project is funded through the Australian Research Council Linkage Project LP0349322 in collaboration with Mono Pumps Australia while a 2005 Mondialogo Award

(UNESCO/DaimlerChrysler Partnership) funded the project implementation stage. AINSE

Award 2005 Project No 2192 contributed to funding of the analysis at ANSTO. The authors

would like to additionally acknowledge: John Childs (Northern Territory Power and Water; CRC Desert Knowledge), Gil Bowman (Pine Hill Station) for significant help with logistics, and field trial sponsors BP Solar (Australia), GHD Pty. Ltd. (Water Group, Brisbane), Department of Environment and Heritage, New South Wales Department of Commerce, and the Australian National University. The students and taff that participated in the field trial were Kai Ratte, Melanie Werner, Thomas Kruttschnitt, Philipp Sausele and Andreas Broeckmann. The authors Melanie Werner, Thomas Kruttschnitt, Philipp Sausele and Andreas Broeckmann. The aut also thank David Hill and Henri Wong at the Australian Nuclear Science and Technology
Organisation (ANSTO) as well as Helfrid Rossiter (University of Edinburgh) for sample analysis. Organisation (ANSTO) as well as Helfrid Rossiter (University of Edinburgh) for sample analys.
The Overseas Research Students Awards Scheme and James Watt Scholarships funded Laura The Overs
Richards.

\section{References}

[1] United Nations Educational Scientific and Cultural Organization, Water: A Shared Responsibility; The United Nations World Water Development Report 3, 2009.

[2] World Health Organization, Guidelines for Drinking-water Quality: Third Edition Incorporating the First and Second Addenda, Volume 1: Recommendations, 2008.

[3] National Health and Medical Research Council., Australian Drinking Water Guidelines, in: NHMRC National Water Quality Management Strategy, Canberra, 2004.

[4] A.E. Yaroshchuk, Non-steric mechanisms of nanofiltration: superposition of Donnan and [4] A.E. Yaroshchuk, Non-steric mechanisms of nanofiltration:
dielectric exclusion, Sep. Purif. Techno., 22-23 (2001) 143-158.

dielectric exclusion, Sep. Purif. Techno., 22-23 (2001) 143-158. [5] L.D. Nghiem, A.I. Schäfer, Chapter 20: Trace contaminant removal with nanofiltration, in: A. 2005.

[6] B. Tansel, J. Sager, T. Rector, J. Garland, R. Strayer, L. Lanfang, M. Roberts, M.

Hummerick, J. Bauer, Significance of hydrated radius and hydration shells on ionic permeability during nanofiltration in dead end and cross flow modes, Sep. Purif. Technol., 51 (2006) 40-47. [7] C. Bellona, J.E. Drewes, The role of membrane surface charge and solute physio-chemical properties in the rejection of organic acids by NF membranes, J. Membr. Sci., 249 (2005) 227 234.
[8] J.J. Qin, M.H. Oo, H. Lee, B. Coniglio, Effect of feed $\mathrm{pH}$ on permeate $\mathrm{pH}$ and ion rejection under acidic conditions in NF process, J. Membr. Sci., 232 (2004) 153-159.

[9] J. Schaep, C. Vandecasteele, A.W. Mohammad, W.R. Bowen, Modelling the retention of ionic components for different nanofiltration membranes, Sep. Purif. Technol., 22-23 (2001) 169179.

[10] B. Van der Bruggen, A. Koninckx, C. Vandecasteele, Separation of monovalent and divalent ions from aqueous solution by electrodialysis and nanofiltration, Water Res., 38 (2004) 1347 1353.

[11] L. Paugam, C.K. Diawara, J.P. Schlumpf, P. Jaouen, F. Quéméneur, Transfer of monovalent anions and nitrates especially through nanofiltration membranes in brackish water conditions, Sep. Purif. Technol., 40 (2004) 237-242.

[12] CRC Handbook of Chemistry and Physics, 76th ed., CRC Press, 1995.

[13] M. Mänttäri, A. Pihlajamäki, M. Nyström, Effect of $\mathrm{pH}$ on hydrophilicity and charge and [13] M. Mänttäri, A. Pihlajamäki, M. Nyström, Effect of pH on hydrophilicity and charge and their effect on the $311-320$

[14] L.A. Richards, B.S. Richards, H.M.A. Rossiter, A.I. Schäfer, Impact of Speciation on Fluoride, Arsenic and Magnesium Retention by Nanofiltration/Reverse Osmosis in Remote Australian Communities, Desalination, 248 (2009).

[15] L. Paugam, S. Taha, G. Dorange, P. Jaouen, F. Quéméneur, Mechanism of nitrate transfer in nanofiltration depending on pressure, $\mathrm{pH}$, concentration and medium concentration, J. Membr. Sci., 231 (2004) 37-46.

[16] A. Seidel, J.J. Waypa, M. Elimelech, Role of Charge (Donnan) Exclusion in Removal of Arsenic from Water by a Negatively Charged Porous Nanofiltration Membrane, Env. Eng. Sci., 18 (2001)

18 (2001). Peeters, M.H.V Mulder, H. Strathmann, Streaming potential measurements as a [17] J.M.M. Peeters, M.H.V. Mulder, H. Strathmann, Streaming potential measurements as a

characterization method for nanofiltration membranes, Colloids Surf., A 150 (1999) 247-259.
[18] J. Schaep, B. Van der Bruggen, C. Vandecasteele, D. Wilms, Influence of ion size and [18] J. Schaep, B. Van der Bruggen, C. Vandecasteele, D. Wilms,
charge in nanofiltration, Sep. Purif. Technol., 14 (1998) 155-162.

charge in nanofiltration, Sep. Purif. Technol., 14 (1998) 155-162.
[19] M.R. Teixeira, M.J. Rosa, M. Nyström, The role of membrane charge on nanofiltration [19] M.R. Teixeira, M.J. Rosa, M. Nyström, The ro
performance, J. Membr. Sci., 265 (2005) 160-166.

[20] J.M.M. Peeters, J.P. Boom, M.H.V. Mulder, H. Strathmann, Retention measurements of nanofiltration membranes with electrolyte solutions, J. Membr. Sci., 145 (1998) 199-209.

[21] C. Labbez, P. Fievet, A. Szymczyk, A. Vidonne, A. Foissy, J. Pagetti, Retention of mineral salts by a polyamide nanofiltration membrane, Sep. Purif. Technol., 30 (2003) 47-55.

[22] G.T. Ballet, A. Hafiane, M. Dhahbi, Influence of operating conditions on the retention of phosphate in water by nanofiltration, J. Membr. Sci., 290 (2007) 164-172.

[23] A.E. Childress, M. Elimelech, Relating Nanofiltration Membrane Performance to Membrane Charge (Electrokinetic) Characteristics, Environ. Sci. Technol., 34 (2000) 3710-3716.

[24] A. Szymczyk, C. Labbez, P. Fievet, A. Vidonne, A. Foissy, J. Pagetti, Contribution of [24] A. Szymczyk, C. Labbez, P. Fievet, A. Vidonne, A. Foissy, J. Pagetti, Contribution of
convection, diffusion and migration to electrolyte transport through nanofiltration membranes, Adv. Colloid Interface Sci., 103 (2003) 77-94

[25] P. Fievet, C. Labbez, A. Szymczyk, A. Vidonne, A. Foissy, J. Pagetti, Electrolyte transpor through amphoteric nanofiltration membranes, Chem. Eng. Sci., 57 (2002) 2921-2931. [26] W.R. Bowen, A.W. Mohammad, Characterization and Prediction of Nanofiltration Membrane Performance - A General Assessment, Trans Inst Chem Eng, 76 (1998) 885-893. [27] S. Lee, R.M. Lueptow, Membrane Rejection of Nitrogen Compounds, Environ. Sci. Technol., 35 (2001) 3008-3018 
[28] B.S. Richards, D.P.S. Capão, A.I. Schäfer, Renewable energy powered membrane technology. 2. The effect of energy fluctuations on performance of a photovoltaic hybrid membrane system, Environ. Sci. Technol., 42 (2008) 4563-4569.

[29] M. Werner, A.I. Schäfer, Social aspects of a solar-powered desalination unit for remote Australian communities, Desalination, 203 (2007) 375-393.

[30] A.I. Schäfer, A. Broeckmann, B.S. Richards, Renewable Energy Powered Membrane Technology. 1. Development and Characterization of a Photovoltaic Hybrid Membrane System, Environ. Sci. Technol., 41 (2007) 998-1003.

[31] E.R. Nightingale, Phenomenological Theory of Ion Solvation. Effective Radii of Hydrated Ions., J. Phys. Chem., 63 (1959) 1381-1387.

[32] H.M.A. Rossiter, M.C. Graham, A.I. Schäfer, Impact of speciation on behaviour of uranium in a solar powered membrane system for treatment of brackish groundwater, Sep. Purif. Technol., $71(2010)$ 90-96.

[33] C.K. Diawara, S.M. Lô, M. Rumeau, M. Pontie, O. Sarr, A phenomenological mass transfer approach in nanofiltration of halide ions for a selective defluorination of brackish drinking water, J. Membr. Sci., 219 (2003).

[34] K. Boussu, Y. Zhang, J. Cocquyt, P.Van der Meeren, A. Volodin, C.Van Haesendonck, J.A. Martens, B.Van der Bruggen, Characterization of polymeric nanofiltration membranes for

systematic analysis of membrane performance, J. Membr. Sci., 278 (2006) 418-427.

[35] J.J. Waypa, M. Elimelech, J.G. Hering, Arsenic removal by RO and NF membranes, Amer. Water Works Assoc. J., 90 (1997) 102.

[36] D. Langmuir, Aqueous Environmental Geochemistry, Upper Saddle River, 1997.

[37] J. Zhou, X. Lu, Y. Wang, J. Shi, Molecular dynamics study on ionic hydration, Fluid Phase Equilib., 194-197 (2002) 257-270.

[38] M.Y. Ki Cor biologically important ions, Biophys. Chem. 99 (2002) 155-168.

\section{Table Caption}

Table 1. Feed water quality at Pine Hill and Ti Tree, including detection limit, Australian guideline, and World Health Organization (WHO) guideline (where applicable)

Table 2. Molecular weight, ionic and hydrated radii for relevant ions.

Table 3. Group 1 retention using BW30, TFC-S, ESPA 4, and NF90 at Pine Hill (for comparison of membrane performance with the same sourcewater) as well as BW30 at Ti Tree (for comparison of the same membrane with different sourcewaters). Where retention is reported as ' $\geq$ ', the calculation was limited by the analytical detection limit (as specified in Table 1).

\section{Figure Captions}

Figure 1. Conditions and results for BW30 operating with renewable energy at Pine Hill over the course of one solar day (sunrise to sunset). Feed TDS is $5770 \mathrm{~g} / \mathrm{L}$ and pH 7.2. Subfigure (A) shows solar irradiance (SI) and flow; (B) flux and pressure; (C) salt retention and SI; and (D) inorganic contaminant retention and SI.

Figure 2. Concentration of feed, UF permeate, NF/RO permeate, and concentrate as a function of $\mathrm{pH}$ for BW30 at Pine Hill of Group 2 precipitating solutes (A) copper; (B) magnesium; (C) manganese; (D) molybdenum; (E) nickel; (F) uranium; $(\mathrm{G})$ vanadium; and $(\mathrm{H})$ zinc. Australian guidelines (if applicable) and detection limits (DL) are shown. 
Richards, L. ; Richards, B.S. ; Schäfer, A.I. ; (2011)

Renewable energy powered membrane technology: Effect of contaminant speciation on retention and membrane deposition,

Journal of Membrane Science, (accepted 26/11/2010).

\section{Table 1}

\begin{tabular}{|c|c|c|c|c|c|}
\hline Solute & $\begin{array}{c}\text { Pine Hill } \\
\text { Concentration } \\
(\mathrm{mg} / \mathrm{L})\end{array}$ & $\begin{array}{c}\text { Ti Tree } \\
\text { Concentration } \\
(\mathrm{mg} / \mathrm{L})\end{array}$ & $\begin{array}{c}\text { Detection } \\
\text { Limit } \\
(\mathrm{mg} / \mathrm{L})\end{array}$ & $\begin{array}{l}\text { Australian } \\
\text { Guideline } \\
\text { (mg/L) (3) }\end{array}$ & $\begin{array}{c}\text { WHO } \\
\text { Guideline } \\
(\mathrm{mg} / \mathrm{L})(2)\end{array}$ \\
\hline Aluminium & $<0.01$ & 0.107 & 0.01 & $0.2^{\mathrm{a}}$ & -- \\
\hline Arsenic & 0.005 & 0.003 & 0.001 & 0.007 & $0.01^{\mathrm{b}}$ \\
\hline Barium & 0.016 & 0.040 & 0.001 & 0.7 & 0.7 \\
\hline Beryllium & $<0.001$ & $<0.001$ & 0.001 & -- & -- \\
\hline Calcium & 60.1 & 30.374 & 0.01 & -- & -- \\
\hline Chloride & 2000 & 436.90 & 0.1 & $250^{\mathrm{a}}$ & -- \\
\hline Chromium & $<0.001$ & $<0.001$ & 0.001 & 0.05 & $0.05^{\mathrm{b}}$ \\
\hline Copper & 0.021 & 0.096 & 0.001 & $1^{\mathrm{a}} ; 2$ & 2 \\
\hline Fluoride & 1.10 & 0.464 & 0.01 & 1.5 & 1.5 \\
\hline Iron & 0.225 & 0.055 & 0.001 & $0.3^{\mathrm{a}}$ & -- \\
\hline Lead & 0.004 & 0.005 & 0.001 & 0.01 & 0.01 \\
\hline Lithium & 0.060 & 0.007 & 0.001 & -- & -- \\
\hline Magnesium & 149 & 38.1 & 0.1 & -- & -- \\
\hline Manganese & 0.007 & 0.002 & 0.001 & $0.1^{\mathrm{a}} ; 0.5$ & $0.4^{\mathrm{a}}$ \\
\hline Molybdenum & 0.005 & $<0.001$ & 0.001 & 0.05 & 0.07 \\
\hline Nickel & 0.003 & 0.005 & 0.001 & 0.02 & 0.07 \\
\hline Nitrate & 19.0 & 58.4 & 0.1 & $50^{c}$ & $50^{c}$ \\
\hline Potassium & 15.0 & 26.0 & 0.03 & -- & -- \\
\hline Selenium & 0.015 & 0.004 & 0.001 & 0.01 & 0.01 \\
\hline Sodium & 1650 & 173 & 0.1 & $180^{\mathrm{a}}$ & -- \\
\hline Strontium & 1.30 & 0.475 & 0.001 & -- & -- \\
\hline Sulfur & 272 & 33.2 & 0.001 & -- & -- \\
\hline Sulfate & 889 & 116 & 1.0 & $250^{\mathrm{a}} ; 500$ & -- \\
\hline Titanium & $<0.001$ & $<0.001$ & 0.001 & -- & -- \\
\hline Uranium & 0.295 & 0.025 & 0.001 & 0.02 & $0.015^{\mathrm{b}}$ \\
\hline Vanadium & 0.022 & 0.0009 & 0.001 & -- & -- \\
\hline Zinc & 0.222 & 0.0008 & 0.001 & $3^{\mathrm{a}}$ & -- \\
\hline TDS & 5700 & 1080 & -- & $500^{\mathrm{a}}$ & $600^{\mathrm{a}}$ \\
\hline $\begin{array}{l}{ }^{\mathrm{a}} \text { Aesthetic-basec } \\
\text { toxicology/epid } \\
\text { recommended to } \\
\text { exposure) }\end{array}$ & $\begin{array}{l}\text { line; }{ }^{b} \text { Provi } \\
\text { sy and/or d } \\
\text { t against } n\end{array}$ & $\begin{array}{l}1 \text { guideline } \mathrm{d} \\
\text { difficulties } \mathrm{r} \\
\text { moglobinae }\end{array}$ & $\begin{array}{l}\text { scientific } \\
\text { ing techn } \\
\text { bottle-fe }\end{array}$ & $\begin{array}{l}\text { certainties re } \\
1 \text { achievabili } \\
\text { nfants (short }\end{array}$ & $\begin{array}{l}\text { garding } \\
\text {; }{ }^{\circ} \text { Guideline } \\
\text { term }\end{array}$ \\
\hline
\end{tabular}

Table 2

\begin{tabular}{|c|c|c|c|c|}
\hline Species & $\begin{array}{l}\text { Molecular } \\
\text { Weight } \\
(\mathrm{g} / \mathrm{mol})\end{array}$ & $\begin{array}{c}\text { Ionic } \\
\text { Radius } \\
\text { (nm) }\end{array}$ & $\begin{array}{c}\text { Hydrated } \\
\text { Radius } \\
\text { (nm) }\end{array}$ & Ref. \\
\hline $\mathrm{K}^{+}$ & 39.10 & $\begin{array}{l}0.133^{\mathrm{a}} \\
0.148 \\
0.138\end{array}$ & $\begin{array}{l}0.331 \\
0.275 \\
0.201\end{array}$ & $\begin{array}{l}{[31]} \\
{[37]} \\
{[38]}\end{array}$ \\
\hline $\mathrm{Na}^{+}$ & 22.99 & $\begin{array}{l}0.095^{\mathrm{a}} \\
0.099 \\
0.102 \\
\end{array}$ & $\begin{array}{l}0.358 \\
0.299 \\
0.178\end{array}$ & $\begin{array}{l}{[31]} \\
{[37]} \\
{[38]}\end{array}$ \\
\hline $\mathrm{Sr}^{2+}$ & 87.62 & $\begin{array}{c}0.113^{\mathrm{a}} \\
0.136\end{array}$ & 0.412 & $\begin{array}{l}{[31]} \\
{[38]}\end{array}$ \\
\hline $\mathrm{Cl}^{-}$ & 35.45 & $\begin{array}{c}0.181^{\mathrm{a}} \\
0.198 \\
0.181\end{array}$ & & $\begin{array}{l}{[31]} \\
{[37]} \\
{[38]}\end{array}$ \\
\hline $\mathrm{SO}_{4}{ }^{2-}$ & 96.06 & $\begin{array}{c}0.290^{\mathrm{a}} \\
0.215 \\
\end{array}$ & 379 & $\begin{array}{l}{[31]} \\
{[38]}\end{array}$ \\
\hline $\mathrm{Ni}^{2+}$ & 58.69 & $\begin{array}{c}0.070^{\mathrm{a}} \\
0.060\end{array}$ & & {$[31]$} \\
\hline $\mathrm{SeO}_{4}^{2-}$ & 142.96 & $0.305^{\mathrm{a}}$ & 0.384 & [31] \\
\hline $\mathrm{MoO}_{4}{ }^{2-}$ & 159.94 & $0.323^{\mathrm{a}}$ & 0 & [31] \\
\hline $\mathrm{Ca}^{2+}$ & 40.08 & $\begin{array}{l}0.099^{\mathrm{a}} \\
0.123\end{array}$ & & {$[31]$} \\
\hline $\mathrm{F}^{-}$ & 19.00 & $\begin{array}{c}0.136^{\mathrm{a}} \\
0.128 \\
0.119\end{array}$ & & $\begin{array}{l}{[31]} \\
{[37]} \\
{[38]}\end{array}$ \\
\hline $\mathrm{NO}_{3}{ }^{-}$ & 62.00 & $0.264^{\mathrm{a}}$ & 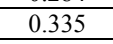 & [31] \\
\hline $\mathrm{Cu}^{2+}$ & 63.55 & $0.072^{\mathrm{a}}$ & 0.419 & [31] \\
\hline $\mathrm{Zn}^{2+}$ & 65.39 & $\begin{array}{c}0.074^{\mathrm{a}} \\
0.074\end{array}$ & $\begin{array}{l}0.430 \\
0.280\end{array}$ & {$[31]$} \\
\hline $\mathrm{Mg}^{2+}$ & 24.31 & $\begin{array}{l}0.065^{\mathrm{a}} \\
0.072\end{array}$ & $\begin{array}{l}0.428 \\
0.300\end{array}$ & $\begin{array}{l}{[31]} \\
{[38]}\end{array}$ \\
\hline $\mathrm{Mn}^{2+}$ & 54.94 & $0.080^{\mathrm{a}}$ & 0.438 & [31] \\
\hline
\end{tabular}


Richards, L. ; Richards, B.S. ; Schäfer, A.I. ; (2011)

Renewable energy powered membrane technology: Effect of contaminant speciation on retention and membrane deposition,

Journal of Membrane Science, (accepted 26/11/2010).

Table 3

\begin{tabular}{cccccc}
\hline Solute & $\begin{array}{c}\text { Retention (\%) } \\
\text { BW30 } \\
\text { Pine Hill }\end{array}$ & $\begin{array}{c}\text { Retention (\%) } \\
\text { TFC-S } \\
\text { Pine Hill }\end{array}$ & $\begin{array}{c}\text { Retention (\%) } \\
\text { ESPA 4 } \\
\text { Pine Hill }\end{array}$ & $\begin{array}{c}\text { Retention (\%) } \\
\text { NF90 } \\
\text { Pine Hill }\end{array}$ & $\begin{array}{c}\text { Retention (\%) } \\
\text { BW30 } \\
\text { Ti Tree }\end{array}$ \\
\hline Arsenic & $\geq 78.9( \pm 5.1)$ & $64.2( \pm 4.7)$ & $\geq 77.6( \pm 4.6)$ & $\geq 77.5( \pm 5.9)$ & $\geq 57.6( \pm 4.5)$ \\
\hline Calcium & $99.6( \pm 0.2)$ & $95.2( \pm 1.1)$ & $98.8( \pm 1.3)$ & $99.5( \pm 0.3)$ & $99.7( \pm 0.2)$ \\
\hline Chloride & $96.4( \pm 2.7)$ & $76.1( \pm 1.8)$ & $89.0( \pm 1.9)$ & $92.5( \pm 3.8)$ & $97.3( \pm 2.9)$ \\
\hline Nitrate & $90.6( \pm 6.7)$ & $51.5( \pm 6.6)$ & $70.0( \pm 7.4)$ & $90.4( \pm 2.0)$ & $90.9( \pm 6.2)$ \\
\hline Potassium & $94.9( \pm 4.1)$ & $78.9( \pm 2.9)$ & $85.7( \pm 3.2)$ & $91.0( \pm 5.2)$ & $97.4( \pm 2.1)$ \\
\hline Selenium & $\geq 93.8( \pm 0.1)$ & $90.0( \pm 3.8)$ & $\geq 92.6( \pm 2.6)$ & $\geq 92.9( \pm 2.6)$ & $\geq 74.3( \pm 3.5)$ \\
\hline Sodium & $96.4( \pm 1.5)$ & $77.4( \pm 2.9)$ & $79.6( \pm 2.2)$ & $87.5( \pm 4.9)$ & $96.2( \pm 1.4)$ \\
\hline Strontium & $99.6( \pm 0.2)$ & $95.7( \pm 0.9)$ & $98.8( \pm 1.4)$ & $99.5( \pm 0.4)$ & $99.7( \pm 0.1)$ \\
\hline Sulfate & $99.5( \pm 0.5)$ & $97.1( \pm 0.6)$ & $99.1( \pm 0.3)$ & $99.5( \pm 0.2)$ & $99.8( \pm 0.1)$ \\
\hline TDS & $94.9( \pm 4.5)$ & $77.7( \pm 2.7)$ & $87.7( \pm 5.9)$ & $91.4( \pm 3.7)$ & $94.4( \pm 6.9)$ \\
\hline & & & &
\end{tabular}

Figure 1

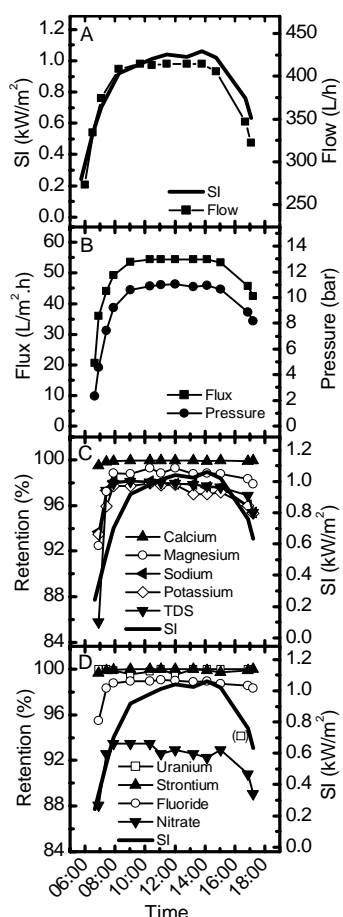


Richards, L. ; Richards, B.S. ; Schäfer, A.I. ; (2011)

Renewable energy powered membrane technology: Effect of contaminant speciation on retention and membrane deposition,

Journal of Membrane Science, (accepted 26/11/2010).

\section{Figure 2}

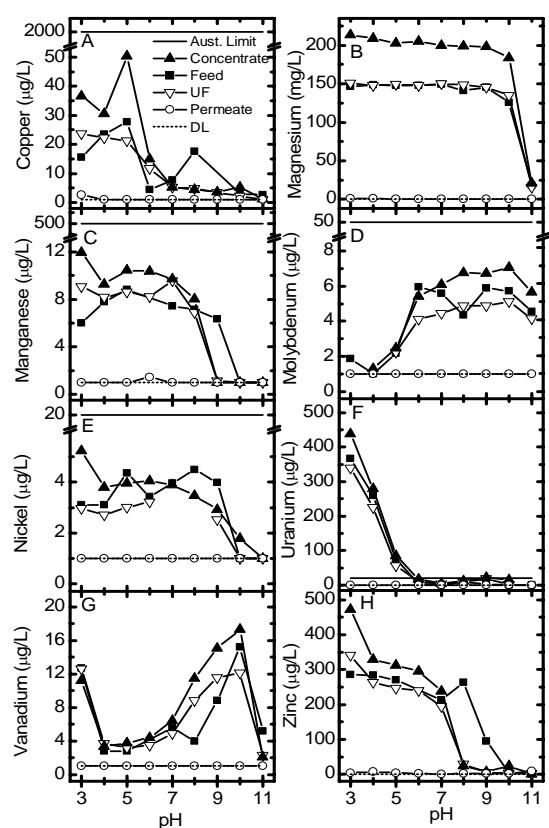

